\title{
Is skeletal muscle mass an optimal marker for postoperative outcomes in lung cancer patients?
}

\author{
Yusuke Takahashi ${ }^{1,2}$, Takeo Nakada ${ }^{1}$, Noriaki Sakakura ${ }^{1}$, Hiroaki Kuroda ${ }^{1}$ \\ ${ }^{1}$ Department of Thoracic Surgery, Aichi Cancer Center Hospital, Nagoya, Japan; ${ }^{2}$ Division of Oncoimmunology, Aichi Cancer Center Research \\ Institute, Nagoya, Japan \\ Correspondence to: Yusuke Takahashi, MD, PhD. Division of Oncoimmunology, Aichi Cancer Center Research Institute, 1-1 Kanoko-den, Chikusa, \\ Nagoya, Aichi 464-8681, Japan. Email: yusuketakahashigts@gmail.com. \\ Provenance: This is an invited article commissioned by the Section Editor Laura Chiara Guglielmetti (Cantonal Hospital Winterthur, Kantonsspital \\ Winterthur, Switzerland). \\ Comment on: Nishimura JM, Ansari AZ, D'Souza DM, et al. Computed Tomography-Assessed Skeletal Muscle Mass as a Predictor of Outcomes in \\ Lung Cancer Surgery. Ann Thorac Surg 2019;108:1555-64.
}

Submitted Oct 25, 2019. Accepted for publication Nov 06, 2019.

doi: $10.21037 /$ jtd.2019.11.21

View this article at: http://dx.doi.org/10.21037/jtd.2019.11.21

Lung resection is a standard therapeutic option for earlystage non-small cell lung cancer (NSCLC) and it is widely performed in developed and developing countries (1). Despite recent progress of imaging technology and surgical devices, postoperative outcomes have not been changed for decades (2,3). For improving postoperative outcomes, appropriate markers that have potential to stratify risk of postoperative outcomes are necessary in preoperative management.

Postoperative outcomes consist of postoperative complications and long-term survival outcomes. Given long-term survival, despite prognostic factors for tumor histologic, molecular, and genomic features have been reported, what reflect the general condition is still poorly understood. The significance of these factors regarded to general condition is going to increase as high aged population increases. Thus, it is demanded to identify preoperative clinical factors that reflect general condition and better predict postoperative complications $(4,5)$ as well as long-term survival $(6,7)$. On the other hand, usefulness of conventional risk factors related to general condition such as age and performance status is limited in perioperative management as it is impossible to improve these factors with any therapeutic options.

Sarcopenia is defined as the physical component of syndromes characterized by significant loss of skeletal muscle mass and function that is related to aging and poor-nutrition status which is associated with high risk of physical disability, poor quality of life, and death (8). Lots of publications demonstrated their association to postoperative survival outcome in various pathologies including cardiovascular $(9,10)$, chronic renal failure (11), and sepsis (12). In addition, its clinical significance in predicting survival outcomes of solid malignancies has been well documented (13-16). However, the clinical significance of sarcopenia in patients undergoing lung resection has not been well understood. Especially, prognostic significance of sarcopenia in thoracic surgery for NSCLC is controversial.

On the backgrounds, a systematic review by Nishimura et al. demonstrated the clinically useful findings that CTassessed measurement of skeletal muscle mass is a significant predictor for postoperative complications (odds ratio 2.51; 95\% CI: $1.55-4.08, \mathrm{P}<0.001)$ and worse long-term survival (hazard ratio 2.31 ; 95\% CI: $1.26-4.24, \mathrm{P}=0.007)(17)$. The methodology of the study is appropriate and quite sophisticated using abundant literature systematically searched so that the findings seem to be robust. Whereas, it is still unknown whether sarcopenia is a cause of the unfavorable outcomes in patients undergoing lung resection for NSCLC. Moreover, it should be resolved if the CTassessed skeletal muscle mass is an optimal marker of sarcopenia.

In considering future routine use of preoperative CTassessed skeletal muscle mass, the optimal cut-off value 
is another point. Of note, the prevalence of sarcopenia is $42.8 \%$ in average (range: $22.4-55.8 \%$ ) among the 1,010 patients in the study objectives (17). Since the prevalence seems quite high, it may be more demanding to improve the sarcopenic condition in patients before treatment. Some clinical trials demonstrated that physical exercise and nutrition intervention including supplementation of proteins, essential amino acids, and $\beta$-hydroxy- $\beta$ methylbutyrate, have positive impact on muscle mass and function (18). Although the influence of the surgical outcomes especially in patients with solid malignancies, the findings may be a fundamental data of the future clinical trial in patients undergoing lung resection for NSCLC.

In summary, the paper of Nishimura clearly demonstrated that CT-assessed skeletal muscle mass is significantly associated with higher risk of postoperative complications as well as long-term survival outcomes among the patients undergoing lung resection for NSCLC. It is a simple and cost-effective method to evaluate sarcopenic condition because chest and abdominal CT is widely available in the population. It may be required to investigate optimal cut-off value to appropriately reflect sarcopenia in CT-assessed skeletal muscle mass. In addition, therapeutic options should be clinically useful to improve outcomes of the sarcopenic patients as the prevalence of sarcopenia is not low. Better risk stratification of postoperative complication and survival may improve our clinical practice and impact on medical economy in the near future.

\section{Acknowledgments}

We thank Marissa Mayor of Washington University Department of Surgery for her editorial assistance.

\section{Footnote}

Conflicts of Interest: The authors have no conflicts of interest to declare.

Ethical Statement: The authors are accountable for all aspects of the work in ensuring that questions related to the accuracy or integrity of any part of the work are appropriately investigated and resolved.

\section{References}

1. Jemal A, Bray F, Center MM, et al. Global cancer statistics. CA Cancer J Clin 2011;61:69-90.
2. Milano MT, Strawderman RL, Venigalla S, et al. Nonsmall-cell lung cancer after breast cancer: a populationbased study of clinicopathologic characteristics and survival outcomes in 3529 women. J Thorac Oncol 2014;9:1081-90.

3. Molina JR, Yang P, Cassivi SD, et al. Non-small cell lung cancer: epidemiology, risk factors, treatment, and survivorship. Mayo Clin Proc 2008;83:584-94.

4. Takahashi Y, Matsutani N, Morita S, et al. Predictors of long-term compensatory response of pulmonary function following major lung resection for non-small cell lung cancer. Respirology 2017;22:364-71.

5. Takahashi Y, Matsuda M, Aoki S, et al. Qualitative Analysis of Preoperative High-Resolution Computed Tomography: Risk Factors for Pulmonary Complications After Major Lung Resection. Ann Thorac Surg 2016;101:1068-74.

6. Takahashi Y, Horio H, Hato T, et al. Prognostic Significance of Preoperative Neutrophil-Lymphocyte Ratios in Patients with Stage I Non-small Cell Lung Cancer After Complete Resection. Ann Surg Oncol 2015;22 Suppl: S1324-31.

7. Kuroda H, Yoshida T, Arimura T, et al. Contribution of smoking habit to the prognosis of stage I KRASmutated non-small cell lung cancer. Cancer Biomark 2018;23:419-26.

8. Cruz-Jentoft AJ, Bahat G, Bauer J, et al. Sarcopenia: revised European consensus on definition and diagnosis. Age Ageing 2019;48:16-31.

9. Okamura H, Kimura N, Tanno K, et al. The impact of preoperative sarcopenia, defined based on psoas muscle area, on long-term outcomes of heart valve surgery. J Thorac Cardiovasc Surg 2018;157:1071-9.e3.

10. Narumi T, Watanabe T, Kadowaki S, et al. Sarcopenia evaluated by fat-free mass index is an important prognostic factor in patients with chronic heart failure. Eur J Intern Med 2015;26:118-22.

11. Hanatani S, Izumiya Y, Onoue Y, et al. Non-invasive testing for sarcopenia predicts future cardiovascular events in patients with chronic kidney disease. Int J Cardiol 2018;268:216-21.

12. Ji Y, Cheng B, Xu Z, et al. Impact of 10sarcopenic obesity on 30-day mortality in critically ill patients with intraabdominal sepsis. J Crit Care 2018;46:50-4.

13. Chakedis J, Spolverato G, Beal EW, et al. Pre-operative Sarcopenia Identifies Patients at Risk for Poor Survival After Resection of Biliary Tract Cancers. J Gastrointest Surg 2018;22:1697-708.

14. Okumura S, Kaido T, Hamaguchi Y, et al. Impact of Skeletal Muscle Mass, Muscle Quality, and Visceral 
Adiposity on Outcomes Following Resection of Intrahepatic Cholangiocarcinoma. Ann Surg Oncol 2017;24:1037-45.

15. Psutka SP, Carrasco A, Schmit GD. Sarcopenia in patients with bladder cancer undergoing radical cystectomy: impact on cancer-specific and all-cause mortality. Cancer 2014;120:2910-8.

16. Peng P, Moynagh M, Boorjian S, et al. Impact of sarcopenia on outcomes following resection of pancreatic adenocarcinoma. J Gastrointest Surg 2012;16:1478-86.

17. Nishimura JM, Ansari AZ, D'Souza DM, et al. Computed Tomography-Assessed Skeletal Muscle Mass as a Predictor of Outcomes in Lung Cancer Surgery. Ann Thorac Surg 2019;108:1555-64.

18. Beaudart C, Dawson A, Shaw SC, et al. Nutrition and physical activity in the prevention and treatment of sarcopenia: systematic review. Osteoporos Int 2017;28:1817-33.
Cite this article as: Takahashi Y, Nakada T, Sakakura N, Kuroda H. Is skeletal muscle mass an optimal marker for postoperative outcomes in lung cancer patients? J Thorac Dis 2019;11(12):5643-5645. doi: 10.21037/jtd.2019.11.21 